\title{
BMJ Open Choosing Healthy Eating for Infant Health (CHErIsH) study: protocol for a feasibility study
}

\author{
Karen Matvienko-Sikar, ${ }^{1}$ Elaine Toomey, ${ }^{2}$ Michelle Queally, ${ }^{3}$ Caragh Flannery, ${ }^{1}$ \\ Kate O Neill, ${ }^{1}$ Ted G Dinan, ${ }^{4,5}$ Edel Doherty, ${ }^{3}$ Janas M Harrington, ${ }^{1}$ \\ Catherine Hayes, ${ }^{\circ}{ }^{6}$ Caroline Heary, ${ }^{2}$ Marita Hennessy, ${ }^{7}$ Colette Kelly, ${ }^{8}$ \\ Sheena M Mc Hugh, ${ }^{1}$ Jenny McSharry, ${ }^{7}$ Catherine Stanton, ${ }^{5,9}$ Tony Heffernan, ${ }^{10}$ \\ Molly Byrne, ${ }^{11}$ Patricia M Kearney ${ }^{1}$
}

To cite: Matvienko-Sikar K, Toomey E, Queally M, et al. Choosing Healthy Eating for Infant Health (CHErlsH) study: protocol for a feasibility study. BMJ Open 2019;9:e029607. doi:10.1136/ bmjopen-2019-029607

- Prepublication history for this paper is available online. To view these files, please visit the journal online (http://dx.doi. org/10.1136/bmjopen-2019029607).

KM-S and ET contributed equally.

Received 1 February 2019 Revised 5 April 2019 Accepted 30 May 2019
Check for updates

(C) Author(s) (or their employer(s)) 2019. Re-use permitted under CC BY-NC. No commercial re-use. See rights and permissions. Published by BMJ.

For numbered affiliations see end of article.

Correspondence to Dr Karen Matvienko-Sikar; karen.msikar@ucc.ie

\section{ABSTRACT}

Introduction Childhood obesity is a public health challenge. There is evidence for associations between parents' feeding behaviours and childhood obesity risk. Primary care provides a unique opportunity for delivery of infant feeding interventions for childhood obesity prevention. Implementation strategies are needed to support infant feeding intervention delivery. The Choosing Healthy Eating for Infant Health (CHErlsH) intervention is a complex infant feeding intervention delivered at infant vaccination visits, alongside a healthcare professional (HCP)-level implementation strategy to support delivery.

Methods and analysis This protocol provides a description of a non-randomised feasibility study of an infant feeding intervention and implementation strategy, with an embedded process evaluation and economic evaluation. Intervention participants will be parents of infants aged $\leq 6$ weeks at recruitment, attending a participating HCP in a primary care practice. The intervention will be delivered at the infant's 2, 4, 6, 12 and 13 month vaccination visits and involves brief verbal infant feeding messages and additional resources, including a leaflet, magnet, infant bib and sign-posting to an information website. The implementation strategy encompasses a local opinion leader, HCP training delivered prior to intervention delivery, electronic delivery prompts and additional resources, including a training manual, poster and support from the research team. An embedded mixed-methods process evaluation will examine the acceptability and feasibility of the intervention, the implementation strategy and study processes including data collection. Qualitative interviews will explore parent and HCP experiences and perspectives of delivery and receipt of the intervention and implementation strategy. Self-report surveys will examine fidelity of delivery and receipt, and acceptability, suitability and comprehensiveness of the intervention, implementation strategy and study processes. Data from electronic delivery prompts will also be collected to examine implementation of the intervention. A cost-outcome description will be conducted to measure costs of the intervention and the implementation strategy.

Ethics and dissemination This study received approval from the Clinical Research Ethics Committee of the Cork

\section{Strengths and limitations of this study}

- This study provides a robust evidence base for future examination and implementation of the intervention and implementation strategy in primary care by utilising a comprehensive, multi-methods approach to examine feasibility, including an embedded process evaluation, of both a parent-level intervention and a healthcare professional-level implementation strategy.

- A significant strength of this study is the combination of evidence related to current infant feeding guidelines, implementation science and behavioural science to develop both a parent-level intervention and a healthcare professional-level implementation strategy.

- Inclusion of parent and practitioner involvement in the study design and the feasibility trial improves the quality and relevance of this research.

- A further strength is the inclusion of an economic assessment, a cost-outcome description, of the intervention and implementation strategy. While implementation process costs are identified as an important factor in implementation science, these costs are understudied and often overlooked.

- Recruitment and selection, and retention of participants is susceptible to recruitment bias at provider and patient levels.

Teaching Hospitals. Study findings will be disseminated via peer-reviewed publications and conference presentations.

\section{INTRODUCTION}

Childhood obesity tracks to adulthood $^{12}$ and is associated with increased risk of diabetes, ${ }^{3} 4$ hypertension, coronary heart disease and stroke, ${ }^{5-7}$ as well as longterm morbidity and premature mortality. ${ }^{568}$ Though recent evidence suggests some stabilisation of childhood obesity rates, ${ }^{9}$ global prevalence remains high. ${ }^{10}$ In 2016, there were approximately 41 million children aged 
$<5$ years with obesity or overweight. ${ }^{11}$ In Organisation for Economic Co-operation and Development countries, it is estimated that one in six children are living with overweight or obesity; in Ireland, this rises to one in four children. ${ }^{12-14}$

Evidence indicates that the period from pregnancy to 2 years of age is a critical window for development and prevention of childhood obesity. ${ }^{1516}$ Identified risk factors for childhood obesity within this time frame include maternal factors such as body mass index (BMI), ${ }^{15} 17$ and infant birth weight and growth in infancy. ${ }^{151819}$ There is also evidence for an association between parents' modifiable feeding behaviours and childhood obesity risk. ${ }^{20-24}$ Such behaviours include the initiation and duration of breast feeding, ${ }^{25-27}$ inappropriate bottle use including prolonged use, ${ }^{1528}$ early introduction of solids ${ }^{15290}$ and the types, variety and sensory properties of foods fed to children. ${ }^{31}{ }^{32}$ Parental feeding behaviours are particularly important in infancy because of rapid developmental changes and concurrent developmental and feeding needs. ${ }^{23} 33$ During this period, how parents feed their infant may impact on child weight outcomes via different mechanisms. More rapid weight gain among formula-fed infants ${ }^{34-36}$ is associated with increased risk of childhood obesity $^{15} 18$ 19; conversely, breast feeding is associated with reduced risk of obesity. ${ }^{25}{ }^{37}$ The types of food fed during complementary feeding are also posited to stimulate gut microbiota changes that are associated with overweight. ${ }^{38} 39$ Feeding behaviours such as responsive or non-responsive feeding may influence child obesity risk through development of child self-regulation of energy intake $\mathrm{e}^{202138-40}$ and establishing future child eating behaviours. $^{15} 384142$

Parental feeding behaviours are influenced by multiple factors including demographic characteristics, ${ }^{43-45}$ cost and time constraints ${ }^{46} 47$ and information about infant feeding. ${ }^{46489}$ A recent qualitative evidence synthesis indicated that when parents are confused by conflicting infant feeding information they receive from multiple sources, this can lead to inappropriate feeding behaviours. ${ }^{46}$ Currently, only $44 \%$ of women initiate breast feeding globally, and rates of exclusive breast feeding at 6 months are approximately $40 \%{ }^{50}$; this is despite WHO recommendations to exclusively breast feed until 6 months of age, followed by the introduction of nutritionally adequate food, accompanied by breast feeding up to at least 2 years of age. ${ }^{51}$ There is also evidence that a large proportion of children worldwide start solids before the recommended age. ${ }^{52-54}$ In Ireland, approximately $60 \%$ of infants are breast fed, with $49 \%$ exclusively breast fed, at discharge from maternity hospital ${ }^{55}$ and only $15 \%$ of infants are exclusively breast fed at 6 months $^{56} ; 13.5 \%$ of infants regularly consume solids between 12 and 16 weeks in Ireland, while $47 \%$ of infants regularly consume solids before 5 months. ${ }^{57}$ These figures are high despite national and international guidelines regarding infant feeding. For instance, in Ireland, programmes such as the National
Healthy Childhood Programme (NHCP) and the Nurture Programme aim to provide guidance, advice and support for families during early childhood on topics including infant feeding. An important focus of these programmes is the use of existing healthcare contact points to provide support and advice, and improve consistency in information delivery by healthcare professionals (HCPs).

HCPs are in a unique position to promote healthy and appropriate infant feeding to parents in early childhood due to increased frequency of contact from birth to 2 years. ${ }^{58}{ }^{59} \mathrm{~A}$ recent systematic review demonstrated potential benefits of HCP-delivered interventions, including improved infant feeding and reductions in some child weight outcomes. ${ }^{58}$ While evidence for efficacy of intervention delivery in specific healthcare contexts is unclear, ${ }^{58}$ vaccination visits in primary care provide an opportunity to integrate an early feeding intervention into routine healthcare. For instance, in Ireland, children are entitled to free vaccination services under the Childhood Immunisation Programme at 2, 4, 6, 12 and 13 months; uptake rates are approximately $93 \% .^{60}$ Infant feeding information is not typically provided to parents at these vaccination visits, though infant feeding/nutrition interventions delivered in primary care have been found to be acceptable to parents and HCPs. ${ }^{61} 62$

Recent evidence indicates the importance of supportive trusting relationships between parents and HCPs to facilitate the successful implementation of such interventions. ${ }^{63}$ There is also a need for clear and consistent guidelines and messages regarding infant feeding for both parents and $\mathrm{HCPs}^{46}$ to ensure successful intervention delivery and receipt. ${ }^{63}$ Furthermore, issues with HCP capacity (ie, time and resources) and clarity regarding HCP roles have been reported as important barriers to the implementation and delivery of infant feeding interventions. ${ }^{63}$ Given the importance of support provision, clarity and consistency in HCP delivery of infant feeding information during an existing busy contact point in primary care (ie, the vaccination visit), there is a need to develop appropriate and feasible implementation strategies to support HCPs to deliver such interventions in reallife settings.

This feasibility study will therefore examine both a brief complex parent-level intervention and an implementation strategy targeting the HCPs who will deliver this intervention. The brief complex intervention targets parents to improve infant feeding behaviours in the ages of 2-13 months, and is delivered during primary care-based vaccination visits. The implementation strategy targets HCPs to support their delivery of this clinical intervention via training and additional resources. This feasibility study is not intended to function as a 'scale model' of a larger trial but will instead address uncertainties about feasibility of the intervention, the implementation strategy, economic evaluation and the overall study procedures as recommended by existing guidance on the development of complex interventions. ${ }^{645}$ 


\section{Aims}

The primary aim of the Choosing Healthy Eating for Infant Health (CHErIsH) pilot feasibility study is to collect and examine data on the acceptability and feasibility of the delivery of a brief infant feeding intervention by HCPs to parents at child vaccination visits, and the strategy to support implementation of this intervention in primary care for HCPs. This will facilitate the refinement of the intervention and its implementation strategy, and inform the next step of the CHErIsH study, such as a definitive trial.

Specifically, the CHErIsH feasibility study will address the following research questions:

1. Are the intervention content, delivery and implementation procedures acceptable to parents who will receive the intervention, and HCPs who will deliver the intervention?

2. Are the data collection processes, including mode and duration of data collection and outcome measures used, acceptable to parents and HCPs?

3. Is the intervention feasible to deliver in primary care practice, in terms fidelity of delivery and receipt of the intervention?

4. Is the study feasible in terms of recruitment and retention procedures and data collection?

5. What are the costs associated with the intervention and its implementation strategy?

\section{METHODS \\ Design}

The CHErIsH study is a non-randomised feasibility study, including an embedded process evaluation and economic evaluation.

\section{Patient and public involvement}

One of the study co-investigators and co-authors (TH) is an HCP in primary care practice and was involved in the development of all aspects of the study. A CHErIsH patient and public involvement (PPI) group was established, comprising five mothers, including one grandmother, and three fathers, including one grandfather. The CHErIsH PPI group has advised on study design, measurement and study materials.

\section{Participants}

\section{Primary healthcare centre providers}

The intervention will be delivered in the Mallow Primary Healthcare Centre (MPHC) in Cork, Ireland. MPHC is a large primary care centre, which includes three separate primary care practices. MPHC has approximately 20 general practitioners (GPs) and 12 practice nurses (PNs), and a large nationally representative catchment population. Approximately, 450 infants are delivered by women attending MPHC per year. HCPs will be eligible for inclusion if they are involved in the delivery of routine infant vaccinations and can participate in training to deliver the intervention. In Ireland, routine vaccinations are typically delivered by PNs or GPs.
Parents

Parents or primary caregivers (herein referred to as 'parents') are eligible for inclusion if they meet the following criteria:

- Parent of an infant $\leq 6$ weeks of age at study recruitment.

- Intends to attend a participating GP and/or PN in the primary care centre for child's vaccination visits.

- Is over 18 years of age.

- Can provide written informed consent to participate.

\section{Recruitment}

Healthcare professionals

All eligible HCPs will be invited to participate in the study, and all HCPs within each of the three MPHC practices need to consent and undergo training in order for the intervention to be delivered within that practice. Recruitment will be facilitated and supported by a local opinion leader $^{66}(\mathrm{TH})$, who is a GP based in MPHC. The local opinion leader will liaise with the manager of primary care centre and also identify an existing healthcare centre staff member as a designated onsite administrator. The primary care centre manager will facilitate recruitment of GPs and PNs by providing study information leaflets, invitation sheets and consent forms to all eligible GPs and PNs. On completion, consent forms will be returned to the designated onsite administrator and stored securely until collected by the research team. Alternatively, consent forms will be returned directly to a member of the CHErIsH research team in MPHC prior to commencing intervention training.

As part of the embedded process evaluation, GPs and PNs who consented to participate in the study will be contacted following intervention cessation and invited to participate in qualitative interviews. Purposive sampling will be used to identify HCPs with differing levels of reported acceptability and fidelity of delivery based on the quantitative data collected. It is expected that interviews will be conducted with an initial sample size of 10 HCPs, with a stopping criterion of an additional 5 HCP interviews conducted without development of additional topics or themes. ${ }^{67}$

See figure 1 for recruitment flowchart.

\section{Parents}

All parents of infants $\leq 6$ weeks of age registered at the primary care centre, and who are scheduled to attend vaccination visits with a participating GP and/or PN, will be identified by the onsite study administrator. Two approaches to recruitment to the intervention will be used (see figure 1).

1. Remote recruitment

a. A letter of information and invitation, an informed consent form, and baseline questionnaire will be posted to all potential participants' home addresses from MPHC before the infant is 6 weeks of age.

b. Signed informed consent forms can be returned at the 2 or 6 week visit with the GP. Parents who have not 
HCP Recruitment

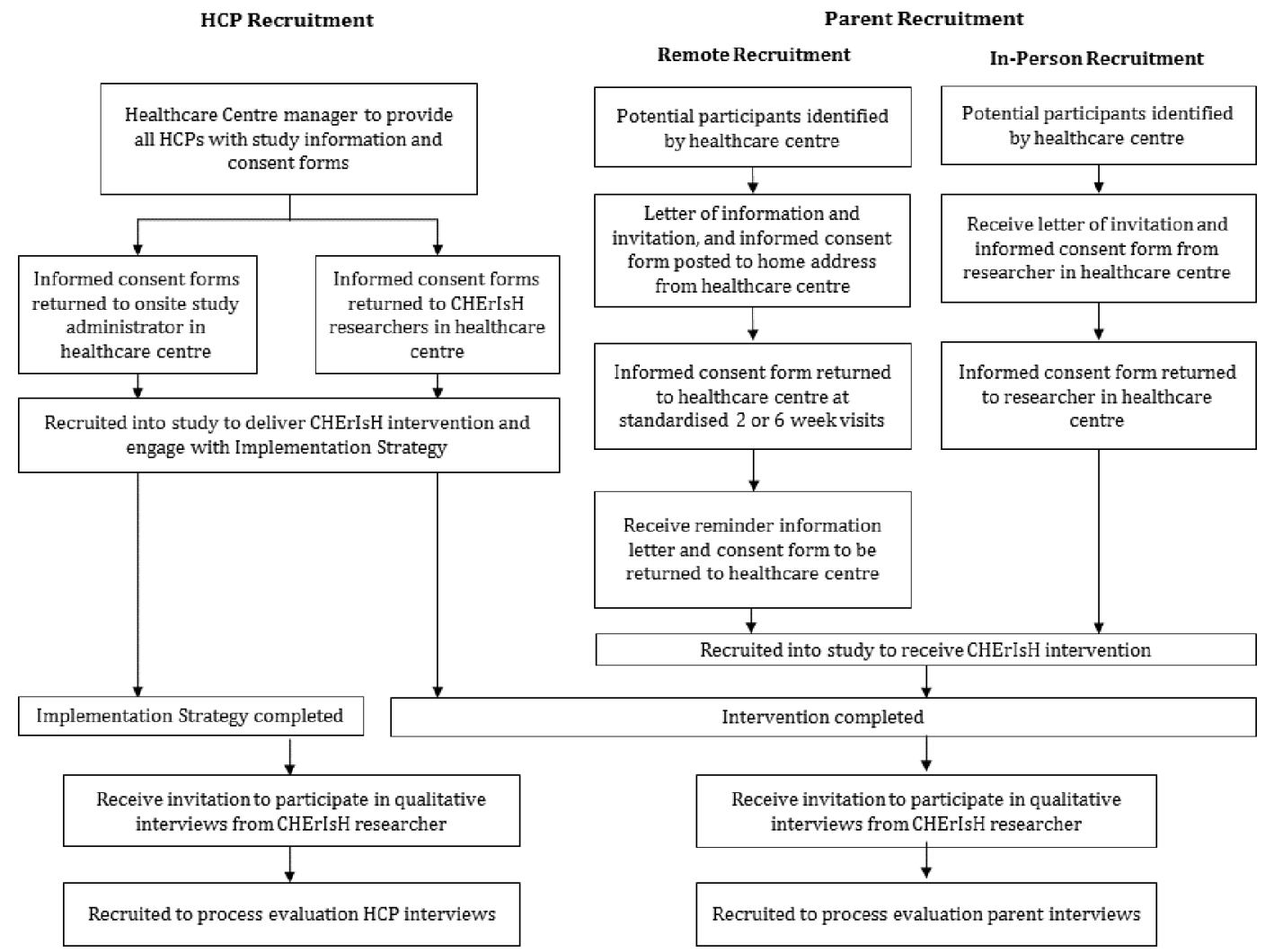

Parent Recruitment

Figure 1 Approaches to HCP and parent recruitment. $\mathrm{CHErlsH}$, Choosing Healthy Eating for Infant Health; HCP, healthcare professional.

returned their consent form within 2 weeks after receiving their recruitment letter will receive a reminder invitation and informed consent form from MPHC.

2. In-person recruitment

a. A CHErIsH researcher will be present in MPHC at times identified by the designated MPHC on-site administrator as suitable for participant recruitment.

b. Eligible parents attending MPHC will be provided with a letter of information and invitation, and an informed consent form by the CHErIsH researcher in MPHC.

c. Signed informed consent forms can be returned to the CHErIsH researcher in MPHC.

Recruitment posters and information leaflets will also be displayed in the MPHC waiting areas. It will be made clear to parents that they do not have to participate in study data collection but that all parents attending the healthcare centre will still receive brief infant feeding messages from their GP and/or PN. This is to minimise HCP burden for delineating between participating and non-participating parents during the vaccination visit. Also, parents routinely receive information on infant care including infant feeding in the first 2 years of life, and so this intervention will not pose any risk or additional burden.

Following intervention cessation, a sample of parents who consent to participate in the CHErIsH intervention will be invited to take part in a single semi-structured qualitative interview as part of the process evaluation. A purposive sampling approach will be used to select parents for interview based on data from study measures (eg, high and low socioeconomic status; parents who breast fed or formula fed). This will ensure maximum variation in the sample for interview in terms of demographic characteristics and study outcomes. As for HCP interviews, parent interviews will be conducted with an initial sample size of 15 parents, with a stopping criterion of an additional 5 parent interviews conducted without development of additional topics or themes. ${ }^{67}$

\section{Intervention and implementation strategy}

The CHErIsH study involves a brief complex intervention targeting parents to improve infant feeding behaviours in the ages of 2-13 months. The intervention will be delivered during routine vaccination visits, alongside an implementation strategy targeting HCPs to support the delivery of this intervention in primary care. The intervention and implementation strategy are described below; full details of the theory-based development of the intervention and implementation strategy are in preparation for publication.

Parent-level intervention

The intervention will be delivered to parents by PNs and/ or GPs in MPHC at each of the vaccination visits, prior to administration of the vaccination. These vaccination visits take place at 2, 4, 6, 12 and 13 months (see figure 2). The intervention was developed based on the findings 


\section{$\leq 6$ weeks $\leq 2$ months 2 months 4 months 6 months 12 months 13 months

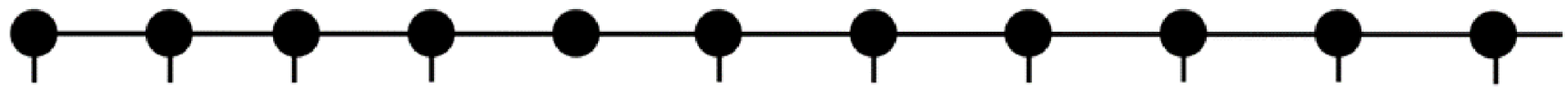 \\ HCP $\mathrm{T}_{\mathrm{HCP}} 1$ data $\mathrm{HCP} \quad \mathrm{T}_{\mathrm{HCP}} 2$ data Parent $\mathrm{T}_{\mathrm{p}} 1$ data Intervention Intervention $-\mathrm{T}_{\mathrm{p}} 2$ data Intervention -Intervention recruitmentcollection training collection recruitment collection delivery delivery collection delivery delivery \\ -Intervention \\ delivery \\ $-\mathrm{T}_{\mathrm{p}} 3$ data \\ collection \\ $-\mathrm{T}_{\mathrm{HCP}} 3$ data \\ collection}

Figure $2 \mathrm{CHErlsH}$ timeline including timing of intervention and implementation strategy delivery, and data collection for parents and healthcare professionals. CHErlsH, Choosing Healthy Eating for Infant Health; HCP, healthcare professional.

of our preparatory work ${ }^{46} 586368-70$ and was guided by the Behaviour Change Wheel, ${ }^{71}$ a systematic behaviour change intervention development framework, to understand, identify and specify intervention functions, content and implementation options. Specific behaviour change techniques (BCTs) identified in our preparatory work were also included, following the Behaviour Change Technique Taxonomy V1. ${ }^{72}$ The theoretical underpinning of the intervention is based on The Theory of Planned Behaviour ${ }^{73}$ (TPB), Responsive Feeding, ${ }^{20}$ Social Cognitive Theory $^{74}$ (SCT) and Family Systems Theory ${ }^{75}$ (FST). Following the TPB, parents' attitudes, perceived behavioural control and norms about infant feeding may influence their feeding behaviours. ${ }^{76}$ Responsive Feeding emerges from responsive parenting and involves appropriate, prompt and consistent feeding interactions and responses to child hunger and satiety cues, ${ }^{20} 3940$ which can influence children's self-regulation of energy intake. SCT is the most commonly applied theory in infant feeding interventions to prevent childhood obesity, ${ }^{78}$ and adopts a broader view of feeding that encompasses personal, behavioural and environmental factors. FST views the family as a system in which each part of the system affects the others in an interconnected manner; as such, parenting practices occur that can impact all family function, including child behavioural and health outcomes, which can in turn influence the family system. ${ }^{79}$ Any behavioural changes related to infant feeding must be acceptable to the existing structures such that they do not upset the stability of the family system. ${ }^{70}$

As such, this intervention consists of (1) verbally delivered prespecified infant feeding messages and (2) provision of additional infant feeding resources including an information leaflet, a magnet, an infant bib and access to an informational website.

\section{Verbal infant feeding messages}

Verbal messages delivered at each vaccination visit are outlined in table 1 . These messages have been developed in consultation with the Irish Health Service Executive (HSE) NHCP and the Nurture Programme to ensure consistency with Irish national strategies. Messages are timed to coincide with vaccination visits and provide infant feeding information and support. As outlined in table 1, messages focus on appropriate milk feeding and establishing complementary feeding and solid food introduction in relation to timing and practical guidance around processes of feeding. There is a focus on positive and enjoyable aspects of feeding based on parental reports of the importance of this aspect for their feeding experiences. ${ }^{43}$ The feeding environment is also addressed, as is sleep in relation to not using feeding to promote sleep.

\section{Additional resources}

Parents will be provided with a single-standard information leaflet at vaccination visits. This leaflet restates the brief infant feeding messages in table 1 and includes signposting to the Irish HSE NHCP Child Health website ( www.mychild.ie). This website has been designed by the NHCP to provide empirically based childcare information, including infant feeding information and managing emotional aspects of childcare. Parents will be provided with a CHErIsH study fridge magnet containing the key infant feeding messages and sign-posting to the Child Health website, and a CHErIsH infant bib that will also sign-post to the Child Health website.

\section{Healthcare professional-level implementation strategy}

The HCP-level implementation strategy is a multi-faceted implementation strategy ${ }^{80}$ and aims to ensure that HCPs are provided with the supports necessary to deliver the intervention as intended. The selection of strategy components within the HCP-level implementation strategy was based on the findings of our preparatory work, ${ }^{46} 586370$ and guided by the Behaviour Change Wheel framework. ${ }^{71}$ The multi-faceted strategy will consist of (1) use of a local opinion leader, (2) incentivised HCP training, (3) distribution of supporting HCP resources and educational materials, (4) electronic delivery prompts for HCPs, (5) awareness raising across all HCPs within the clinical practice and local primary care community and (6) regular 
Table 1 Infant feeding messages to be delivered at vaccination visits

\section{Time point Infant feeding messages}

\begin{tabular}{|c|c|}
\hline 2 months & $\begin{array}{l}\text { Breast milk or a first infant formula provides all the nutrition your baby needs until they are } 26 \text { weeks / } 6 \text { months } \\
\text { old* } \\
\text { The earliest you should consider introducing solid food to your baby's diet is at least } 17 \text { weeks old but ideally } \\
\text { wait until as close to } 26 \text { weeks as possible } \\
\text { Your baby gives you signals when they are hungry or full, like putting his/her hands to his/her mouth when } \\
\text { hungry or turning away or falling asleep when full or not hungry. Crying does not always mean your baby is } \\
\text { hungry }\end{array}$ \\
\hline 4 months & $\begin{array}{l}\text { Breast milk or a first infant formula provides all the nutrition your baby needs until they are } 26 \text { weeks / } 6 \text { months } \\
\text { old } \\
\text { The earliest you should consider introducing solid food to your baby's diet is at least } 17 \text { weeks old but ideally } \\
\text { wait until as close to } 26 \text { weeks as possible, even if your baby seems more hungry at this stage or you would } \\
\text { like to introduce solids to help your baby sleep } \\
\text { When your baby is } 26 \text { weeks old, start introducing solids once per day. Start with one teaspoon and gradually } \\
\text { increase at each meal. Offer the first food with breast or formula milk. Once your baby is eating } 6 \text { teaspoons of } \\
\text { solids at one meal, introduce a second meal per day } \dagger \\
\text { Introduce new foods one at a time to allow your baby get used to the taste and texture } \\
\text { Your baby gives you signals when they are hungry or full, like putting his/her hands to his/her mouth when } \\
\text { hungry or turning away or falling asleep when full or not hungry. Crying does not always mean your baby is } \\
\text { hungry }\end{array}$ \\
\hline
\end{tabular}

6months
Breast feeding continues to be important from 6 months, as other foods are introduced, for up to the first
If not breast fed, your baby should remain on a First infant milk, there is no need to move to a 'number 2 ' or
'follow on' infant formula.
It is important to not delay introduction of solids beyond 26 weeks or 6 months
Start by introducing solids once per day. Start with one teaspoon and gradually increase at each meal. Offer
the first food with breast or formula milk. Once your baby is eating 6 teaspoons of solids at one meal, introduce
a second meal per dayt
Introduce new foods one at a time to allow your baby get used to the taste and texture
Progress through the stages and consistencies, and include fruits and vegetables at each stagef
Teaching your child to eat and helping them learn new tastes can be fun
Your child is getting better at letting you know when they are hungry or full, so continue to watch for and
respond to their signals. For example, if your child signals that they are full, you should not try and get them to
finish the meal

12 months Breast feeding continues to be important for up to the first 2 years and beyond*

- Meals should be eaten without distractions such as televisions and mobile phones

- If you are/were formula feeding, your baby should now have full fat cow's milk, your baby no longer needs infant formula milk§

- Your child is getting better at letting you know when they are hungry or full, so continue to watch for and respond to their signals. For example, if your child signals that they are full, you should not try and get them to finish the meal

13 months
Ereast feeding continues to be important for up to the first 2 years and beyond*
Eeals should be eaten without distractions such as televisions and mobile phones
If you are/were formula feeding, your baby should now have full fat cow's milk, your baby no longer needs
infant formula milk§
Your child is getting better at letting you know when they are hungry or full, so continue to watch for and
respond to their signals. For example, if your child signals that they are full, you should not try and get them to
finish the meal

*Message only delivered to parents of infants currently being breast fed.

†Message delivered to parents who have not yet begun introducing solids.

$\ddagger$ Message not delivered if parents are using baby-led weaning approach.

§Only delivered to healthy child. 
communication with the CHErIsH study team and provision of local technical assistance.

\section{Use of a local opinion leader}

The local opinion leader (TH) is GP based in MPHC in a senior leadership role. In addition to facilitating recruitment, the local opinion leader will play an important role in liaising with HCP staff from all three clinics including other senior decision-making staff as well as the staff who will be required to deliver the intervention and influencing their participation.

\section{Incentivised HCP training}

All eligible HCPs will be invited to attend the CHErIsH HCP training. Accredited continuing professional development (CPD) points will be offered as an incentive for participation to maximise attendance and engagement. Training involves two 40-60 min group-based sessions occurring during pre-existing primary care centre lunchtime CPD meetings. As these existing meetings are also typically attended by other HCPs, including public health nurses (PHNs) and community dieticians, training sessions will be open to all HCPs for inclusivity and also to promote consistency in feeding messages. Additional training may be conducted to accommodate GPs and $\mathrm{PNs}$, if requested. The HCP training will be delivered by a CHErIsH study researcher in conjunction with a dietician member of the NHCP Nurture programme team with expertise in infant nutrition and primary care practice. Training will be standardised using PowerPoint slides and the HCP training manual, pre-developed by the study team with input from the HSE to ensure consistency with NHCP/Nurture national strategies and will address the following:

- Information on and rationale for the CHErIsH study and its aims.

- Information on current national feeding guidelines and recommendations.

- Information on feeding issues including, for example, how to start introducing solids.

- Introduction and overview of the parent-level intervention.

- Training in delivery of intervention content and materials.

- Overview of study procedures and protocol and requirements from participating HCPs.

Distribution of supporting HCP resources and educational materials HCP educational materials and supporting resources that have been developed by the study team with input from the NHCP/Nurture programme team to ensure consistency with HSE national strategies will be distributed to HCPs during the training. These resources consist of a HCP training manual, a CHErIsH poster to be put in rooms where vaccinations take place, and sign-posting to further training and resources for HCPs regarding infant feeding. In addition, HCPs will also be provided with the parent resources (ie, information leaflets, magnets and bibs and sign-posting to NHCP website).

\section{Electronic delivery prompts for HCPS}

Electronic delivery prompts via existing electronic systems in the primary care centre will be used as a reminder to prompt HCPs to deliver the intervention, and to record delivery of the intervention. Prompts will be automatically programmed to appear at the start of each vaccination visit, and will ask HCPs to click whether the intervention components (ie, brief messages, leaflet, infant bib and magnet) were delivered or not.

\section{Awareness-raising across all HCPS}

To raise awareness of the study and thus potentially mitigate inconsistency of infant feeding messages across all HCPs ${ }^{46}$ study information leaflets will also be provided to PHNs and community dieticians working within the geographical remit of the primary care centre by CHErIsH study team via the local opinion leader and primary care centre manager. To avoid contamination, it will be clarified that only GPs and PNs will deliver intervention components in MPCH and that information provided serves the purpose of promoting awareness about the intervention should any participating parents wish to discuss it with them.

Regular communication with the CHErlsH study team and provision of local technical assistance

To promote adherence to the intervention and to deliver assistance in case of implementation issues, HCPs will be informed and encouraged to contact the onsite study administrator if any issues related to the implementation of the intervention are encountered. The research team will initiate bi-weekly phone calls with the onsite study administrator so that any issues can be reported, documented and addressed.

\section{Process evaluation}

A process evaluation will be conducted using a comprehensive mixed-methods approach, informed by the National Institute of Health's Behaviour Change Consortium $^{81}$ treatment fidelity guidelines in conjunction with the Medical Research Council guidance for process evaluation of complex interventions. ${ }^{64}$ This involves assessing fidelity of implementation and any potential adaptations, hypothesised mechanisms of action and contextual influences, ensuring that fidelity is considered across five specific fidelity domains ${ }^{81}$ : (1) design, (2) training, (3) delivery, (4) receipt and (5) enactment.

The process evaluation will provide a better understanding of the intervention and implementation processes, ensuring confidence in the validity of feasibility study outcomes and informing a future definitive intervention. Quantitative and qualitative parent and HCP data will be integrated to ensure a comprehensive, multi-perspective approach to exploring the intervention process (see table 2 ). 
Table 2 Process evaluation outline

\begin{tabular}{|c|c|c|}
\hline $\begin{array}{l}\text { Process evaluation } \\
\text { component }\end{array}$ & Specific component to be assessed & Data source \\
\hline Fidelity & $\begin{array}{l}\text { Fidelity of delivery and receipt of parent- } \\
\text { level intervention } \\
\text { Fidelity of enactment of parent-level } \\
\text { behaviours } \\
\text { Fidelity of delivery and receipt of HCP-level } \\
\text { implementation strategy } \\
\text { Fidelity of enactment of HCP-level } \\
\text { implementation strategy }\end{array}$ & $\begin{array}{l}\text { Parent qualitative interviews } \\
\text { Parent questionnaire } \\
\text { Parent fidelity checklist } \\
\text { - Fidelity checklist for HCP training } \\
\text { Audio recordings of HCP training } \\
\text { HCP delivery fidelity checklists } \\
\text { Electronic prompt data } \\
\text { Phone logs } \\
\text { HCP qualitative interviews }\end{array}$ \\
\hline Mechanisms of change & $\begin{array}{l}\text { Parent knowledge and understanding of } \\
\text { infant feeding } \\
\text { Parent self-efficacy } \\
\text { Parent stress and health-related quality of } \\
\text { life } \\
\text { HCP knowledge and awareness of infant } \\
\text { feeding recommendations } \\
\text { HCP attitudes towards infant feeding }\end{array}$ & $\begin{array}{l}\text { Parent questionnaire } \\
\text { Parent qualitative interviews } \\
\text { HCP questionnaire } \\
\text { HCP qualitative interviews }\end{array}$ \\
\hline Contextual influences & $\begin{array}{l}\text { Influences on delivery and receipt of } \\
\text { parent-level intervention } \\
\text { Influences on delivery and receipt of HCP- } \\
\text { level implementation strategy }\end{array}$ & $\begin{array}{l}\text { HCP qualitative interviews } \\
\text { Parent qualitative interviews }\end{array}$ \\
\hline
\end{tabular}

$\mathrm{HCP}$, healthcare professional.

\section{Qualitative data collection}

Qualitative data will be collected from parents and HCPs using semi-structured interviews following intervention completion; these will be conducted in person, where possible, or by phone. Interviews will be conducted to explore intervention implementation and further explore intervention feasibility and reasons for any issues with the intervention or implementation strategy.

\section{Parent interviews}

Interviews will explore parents' experiences and perspectives of the CHErIsH intervention and study procedures, whether they received the intervention as intended and any perceived contextual influences on intervention receipt. It is anticipated that interviews will be conducted in an iterative manner until no new themes or topics are developed. ${ }^{67}$

\section{HCP interviews}

Interviews will follow a semi-structured guide to explore HCPs' perspectives and experiences of the CHErIsH intervention, implementation strategy, research procedures and the overall feasibility and acceptability of the study. Fidelity of intervention delivery will be investigated by exploring whether the intervention was delivered as planned or whether adaptations to the intervention were made during delivery, including elaborating on reasons for any adaptations. Beliefs about the quality of intervention delivery, capacity and resource needs to deliver the intervention, identification of additional training needs and contextual influences on intervention implementation will be explored.

\section{Self-report data collection \\ Parent self-report}

To examine intervention receipt, parents will complete a brief self-developed Likert-style fidelity checklist at middle and end of the intervention assessing intervention components received (eg, 'Did you receive a leaflet about infant feeding?’). An open-ended question will ask parents for their thoughts or comments on the acceptability, suitability and comprehensiveness of the study and intervention procedures, and how these might be improved.

\section{HCP self-report}

To examine fidelity of intervention delivery, a brief Likert-style fidelity checklist will be completed by HCPs following intervention cessation. A set of three previously validated questionnaires ${ }^{82}$ will be used to assess the acceptability, appropriateness and feasibility of the parent-level intervention (following intervention cessation), study procedures (following study cessation) and the CHErIsH training and supporting resources for HCPs (following delivery of HCP training). These are the Acceptability of Intervention Measure, Intervention Appropriateness Measure and Feasibility of Intervention Measure. ${ }^{82}$ HCPs will also be able to provide additional comments using open-ended self-developed questions that will ask if HCPs have further thoughts or comments on the fidelity, 
acceptability, suitability and/or comprehensiveness of the study and intervention procedures, and how these might be improved. At the end of the study, HCPs will also be asked about the usefulness of the CHErIsH implementation strategy for supporting the intervention delivery. HCPs will rate how much they agree that the implementation strategy was useful on a 5-point scale from 'completely agree' to 'completely disagree'.

\section{CHErlsH researcher self-report}

A quantitative self-report checklist will be used by the members of the CHErIsH team delivering the HCP-level training to enhance and assess the fidelity of delivery of each component of the HCP training. The self-report checklist will be reviewed by the CHErIsH researcher and Nurture programme member delivering the CHErIsH HCP-level training prior to training delivery and completed following training delivery. This will be supplemented with direct observation data completed by an independent observer from the CHErIsH team during the training, and by audio recordings of the training. Audio recordings will be independently coded by two members of the research team to identify presence or absence of intended HCP training components and BCTs. The duration of the training sessions will also be recorded.

\section{Electronic data}

Data from the MPHC electronic prompt systems will also be used to record HCP self-reported delivery of the specific intervention components.

\section{Evaluation of reach and recruitment}

Data will be collected on the number of invitations sent to HCPs and parents, the number of acceptances to participate and the number of refusals. Attrition of parents and HCPs will be documented at each data collection time point. Levels of missing data in returned questionnaires will be recorded.

\section{Health economics evaluation}

A cost-outcome description will be undertaken, which is the most appropriate analytic approach in a non-randomised feasibility trial. This analysis will measure costs and outcomes of the CHErIsH intervention and its implementation. Following recommended steps in undertaking economic evaluations, ${ }^{83} 84$ this analysis will be conducted in four stages.

\section{Define the analysis assumptions}

Following the Health Information Quality Authority guidelines, this analysis will assume a healthcare perspective. ${ }^{85}$ The base year for all analyses will be 2017 representing the most recent year for which cost data are available.

\section{Measure healthcare resources for each cost}

Resources used will be identified in relation to multiple components involved in the delivery of the intervention and implementation strategy. Costs incurred and cost savings arising as a consequence of the intervention and implementation strategy will also be identified. This will include all time and resources expended, and costs borne by MPHC including the training and time spent by HCPs and administrative staff involved in the study. Other costs examined will include healthcare resource use related to infant feeding using the Client Service Receipt Inventory ${ }^{86}$ measure completed by parents.

Measure outcomes associated with each cost

Health-related quality of life of the primary caregiver will be evaluated using the standardised validated EQ-5D-5L ${ }^{87}$ and ICE- CAP $^{88}$ self-report surveys.

\section{Conduct a sensitivity analysis}

This analysis will repeat comparisons between resources and outcomes with different assumptions to examine what happens to the total cost of each activity if the underlying costs of the resources that are used are changed.

\section{Quantitative data collection of intervention outcome measures} Quantitative data from participating parents and HCPs will be collected using questionnaires completed by hand, online or by phone. A multimodal approach to data collection has been adopted to maximise questionnaire response rates and reduce participant burden among two populations (parents of infants and HCPs) who have demanding existing schedules and lives. For parents, $T_{p} 1$ data will be collected at study entry, prior to their infant's 2 month vaccination visit (baseline); $\mathrm{T}_{\mathrm{p}} 2$ data will be collected from parents by the infant's 6 month vaccination visit; $\mathrm{T}_{\mathrm{p}} 3$ data will be collected following the infant's 13 month vaccination visit. Parents will receive email or text message reminders to complete $\mathrm{T}_{\mathrm{p}} 2$ or $\mathrm{T}_{\mathrm{p}} 3$ questionnaires. For HCPs, $\mathrm{T}_{\mathrm{HCP}} 1$ data will be collected prior to training (baseline); $\mathrm{T}_{\mathrm{HCP}} 2$ data will be collected immediately after the training and $\mathrm{T}_{\mathrm{HCP}} 3$ data will be collected 11 months after intervention commencement. See figure 2 for timing of data collection.

\section{Parent and child data collection}

\section{Self-report questionnaire}

Data on parent and child characteristics, feeding practices and styles, dietary intake, child health service use, child feeding preferences, knowledge and self-efficacy and parent psychological quality of life will be collected (see table 3). Infant feeding outcomes have been informed by the infant feeding core outcome set for obesity prevention interventions. ${ }^{68}$

\section{Parent information}

Age, gender, relationship to child, number of children (including ages), ethnic/cultural background, relationship status, education level, employment, medical card status, any time taken off work due to infant feeding issues, and any medications (either prescription or overthe-counter) taken in the previous 6 months. 


\begin{tabular}{|c|c|c|c|c|}
\hline Outcome & Measure & $T_{p} 1$ & $T_{p} 2$ & $\mathbf{T}_{\mathrm{p}} \mathbf{3}$ \\
\hline $\begin{array}{l}\text { Parent demographic } \\
\text { information }\end{array}$ & Self-report items and medical records. & $\checkmark$ & $\checkmark$ & $\checkmark$ \\
\hline Infant characteristics & Self-report items and medical records. & $\checkmark$ & $\checkmark$ & $\checkmark$ \\
\hline Feeding practices & $\begin{array}{l}\text { Self-report items about breast feeding, formula feeding, complementary feeding and } \\
\text { feeding environment. }\end{array}$ & $\checkmark$ & $\checkmark$ & $\checkmark$ \\
\hline Child dietary intake & Parent rating of frequency of child consumption of prespecified foods. & & $\checkmark$ & $\checkmark$ \\
\hline Child feeding preferences & $\begin{array}{l}\text { Parent report of child liking of foods included in the dietary intake report by } \\
\text { indicating 'yes', 'no' or 'never tried' (adapted version of the approach of Denney- } \\
\text { Wilson et al. }{ }^{72} 89 \text { ) }\end{array}$ & & $\checkmark$ & $\checkmark$ \\
\hline Infant feeding styles & $\begin{array}{l}\text { The restrictive, pressuring and responsive subscales of the Infant Feeding Styles } \\
\text { Questionnaire. }\end{array}$ & $\checkmark$ & $\checkmark$ & $\checkmark$ \\
\hline $\begin{array}{l}\text { Knowledge and self- } \\
\text { efficacy }\end{array}$ & The self-efficacy subscale of Maternal Knowledge and Self-Efficacy scale. ${ }^{74}$ & $\checkmark$ & $\checkmark$ & $\checkmark$ \\
\hline $\begin{array}{l}\text { Infant feeding-related } \\
\text { healthcare costs }\end{array}$ & $\begin{array}{l}\text { Adapted Client Resource Use Questionnaire. }{ }^{75} \\
\text { Parents will also be asked about feeding-related HCP engagement and child } \\
\text { medicine use. }\end{array}$ & $\checkmark$ & $\checkmark$ & $\checkmark$ \\
\hline Parent HRQoL & The standardised EQ-5D-5L ${ }^{76}$ and the ICE-CAP. ${ }^{77}$ & $\checkmark$ & $\checkmark$ & $\checkmark$ \\
\hline Parent stress & The perceived Stress Scale. ${ }^{78}$ & $\checkmark$ & $\checkmark$ & $\checkmark$ \\
\hline $\begin{array}{l}\text { Parent intervention } \\
\text { feedback }\end{array}$ & $\begin{array}{l}\text { Open-ended question on parental thoughts about acceptability, suitability and } \\
\text { comprehensiveness of study and intervention procedures. }\end{array}$ & & $\checkmark$ & $\checkmark$ \\
\hline Fidelity checklist & Self-report checklist of intervention receipt and enactment. & & $\checkmark$ & $\checkmark$ \\
\hline Infant biomarker samples & Infant urine and stool samples. & $\checkmark$ & $\checkmark$ & $\checkmark$ \\
\hline $\begin{array}{l}\text { Parental biomarker } \\
\text { samples }\end{array}$ & Parental saliva samples and breast milk samples* & $\checkmark$ & $\checkmark$ & $\checkmark$ \\
\hline
\end{tabular}

$T_{p} 1$, baseline, prior to infant's 2 month vaccination visit; $T_{p} 2$, by the infant's 6 month vaccination visit; $T_{p} 3$, at infant's 13 month vaccination visit.

*Sample collected only from breastfeeding mothers.

$\mathrm{CHErlsH}$, Choosing Healthy Eating for Infant Health; HCP, healthcare professional; HRQoL, health-related quality of life.

\section{Infant information}

Child's date of birth, gender, birth weight and gestational age; childcare arrangements.

\section{Feeding practices}

Parents will provide information about breast feeding and/or formula feeding, intended and/or actual age of introduction of solids, whether child self-feeds (baby-led weaning), type of food fed to child and feeding environment (use of tablets or television when feeding).

\section{Dietary intake}

Child dietary intake will be assessed by asking parents to rate how often their child eats foods including baby cereal, fruits, vegetables, meat, fish, bread, dairy, fast foods, sweets or treats, cow's milk, fizzy drinks or other drinks. Responses will be recorded on a 7-point scale from 'never' to 'once a day or more'.

\section{Child feeding preferences}

Parental perceptions of child feeding preferences will be measured by asking parents 'Does your child usually like this food' in relation to each of the foods included in the Dietary Intake question, and will rate responses as 'yes', 'no' or 'never tried'. ${ }^{89}$

\section{Infant feeding styles}

Parent's infant feeding styles related to infants and toddlers will be measured using the restrictive, pressuring and responsive subscales of the Infant Feeding Styles Questionnaire. $^{90}$ These subscales include 43 items in total; seven items are asked only at $\mathrm{T}_{\mathrm{p}} 2$ and $\mathrm{T}_{\mathrm{p}} 3$ as they relate to feeding behaviours for older children. Internal consistency of the three subscales of the Infant Feeding Styles Questionnaire range from $\mathrm{r}=0.75$ to $\mathrm{r}=0.92 .^{90}$

\section{Maternal knowledge and self-efficacy}

The self-efficacy subscale of Maternal Knowledge and Self-Efficacy scale is a 7-item scale assessing self-efficacy for infant feeding, which has an internal consistency of $\mathrm{r}=0.94 .^{91}$ Two additional items assess breastfeeding self-efficacy. Three items assessing parents' knowledge of appropriate timing of introduction of solids, and hunger and satiety cues will be included.

\section{Infant feeding-related healthcare costs}

Parents will be asked if they have engaged with different HCPs (eg, GP, lactation consultant, dietician) for issues related to feeding. Adapting the Client Resource Use Questionnaire, ${ }^{92}$ parents will be asked to state the 
number of visits and provide a brief description of these visits (eg, whether visits were covered by health insurance or medical card, or were paid for directly by the parent). Parents will also be asked if their child has taken any medicines for feeding-related issues, including the dose and duration.

\section{Parents health-related quality of life}

Parent health-related quality-adjusted life years will be measured using the standardised EQ-5D- $5 \mathrm{~L}^{87}$ and the ICE-CAP. ${ }^{88}$ The EQ-5D-5L is a 25-item questionnaire, consisting of five domains containing 5 items each. The ICE-CAP is a 20-item questionnaire, consisting of five domains containing 4 items each.

\section{Parenting stress}

Stress will be measured using the Perceived Stress Scale. ${ }^{93}$ This is a 10 -item scale with items rated from 0 (never) to 4 (very often). Items assess how often parents have felt stressed in the last month. This scale has been found to have an internal consistency coefficient of $\mathrm{r}=0.89$ among parents at 4 months postpartum. ${ }^{94}$

\section{Child anthropometric outcomes}

Child weight and length data will be extracted from medical records from the healthcare practice and from information provided by PHNs to the healthcare practice, corresponding to the infant's weight as measured at the routine 2 week and 6 week GP visits, and the 3 month and 9-11 month PHN visit. WHO weight-for-length (WFL) z-scores and BMI z-scores will be calculated at each time point following published standards. ${ }^{95}$ Weight gain over time will also be calculated as change in WFL and BMI z-scores between time points. Body composition will not be assessed in this feasibility study despite its inclusion in the standardised core outcome set for infant feeding interventions ${ }^{68}$ due to resource constraints.

\section{Biomarkers}

Half of all potential participants will be invited to provide maternal and infant biomarker samples during the study. These participants will be randomly assigned, using a random number generator, to receive information at recruitment about collection of biomarker samples and will be invited to collect the samples. If participants consent to participate, they will be sent collection materials prior to each collection time point and instructions on collection of the samples as described below. Participants can opt not to collect samples and still participate in all other aspects of the study.

Infant urine and stool samples will be collected at $\mathrm{T}_{\mathrm{p}} 1$, $\mathrm{T}_{\mathrm{p}} 2$ and $\mathrm{T}_{\mathrm{p}} 3$ (see table 3 ).

- Infant urine samples will be collected using Sterisets Urine collection packs by placing the urine collection pad over the area where the infant passes urine. The pad will be checked at $10 \mathrm{~min}$ intervals for $30 \mathrm{~min}$ until the pad is wet (if the pad is not wet at $30 \mathrm{~min}$ a new pad will be inserted).
- Infant stool samples will be collected by mothers from the infant's nappy and a one teaspoon volume of the stool sample will be transferred to a provided stool sample collection container.

Parental saliva and breast milk samples will be collected at $\mathrm{T}_{\mathrm{p}} 1, \mathrm{~T}_{\mathrm{p}} 2$ and $\mathrm{T}_{\mathrm{p}} 3$ as follows:

- Parental saliva samples will be collected using a Salimetrics saliva swab and storage tube. Samples will be collected by placing the swabs in the mouth until saturated immediately on waking, $30 \mathrm{~min}$ after waking and 45 min after waking.

- A breast milk sample will also be collected from participating breastfeeding mothers, by asking the mother to express the equivalent of a teaspoon volume of breast milk (by hand or using a breast pump).

All samples will be stored by parents in the provided storage containers and refrigerated until returned to MPHC. All sample collection materials will be clearly labelled with the following: study name, participant number, date of birth, sample type, date of collection. All maternal and infant samples will be stored in a refrigerator in the primary care centre until collected by a member of the study team and transferred to a $-80^{\circ} \mathrm{C}$ freezer in the APC Microbiome Ireland Clinical Laboratory in University College Cork. The purpose of the collection of infant urine and stool, and maternal saliva and breast milk, is to examine feasibility and costs of sample collection and storage. As such, samples will not be assayed and examined for the purposes of the current feasibility trial.

\section{Healthcare professional data collection}

\section{Self-report questionnaire}

Data will be collected from GPs and PNs involved in delivering the intervention using a self-report questionnaire as outlined below and in table 4 .

\section{Demographic information}

Data will be collected on age, gender, profession, years qualified, years working in primary care and previous professional or personal experience with infant feeding.

\section{Attitudes towards and knowledge of infant feeding}

An adapted version of the Allcutt and Sweeney survey ${ }^{96}$ will be used to assess knowledge and attitudes towards infant feeding, including breast feeding, formula feeding and solid food introduction.

\section{Analysis}

\section{Qualitative analysis}

All interviews with HCPs and parents will be transcribed verbatim, and interview transcripts will be entered into the NVivo qualitative analysis software programme to facilitate data management, coding and retrieval. Data will be analysed using thematic analysis following the guidelines of Braun and Clarke. ${ }^{97}$ As such, all data will initially be open coded; open codes will then be analysed to generate themes and subthemes, which will be revised and refined through an inductive and iterative process. Analytic rigour will be maintained using the criteria of 


\begin{tabular}{|c|c|c|c|c|}
\hline Outcome & Measure & $\mathrm{T}_{\mathrm{HCP}} 1$ & $\mathbf{T}_{\mathrm{HCP}} 2$ & $\mathbf{T}_{\mathrm{HCP}}{ }^{3}$ \\
\hline Provider demographics & Self-report items & $\checkmark$ & & \\
\hline $\begin{array}{l}\text { Attitudes towards and } \\
\text { knowledge of infant feeding }\end{array}$ & $\begin{array}{l}\text { Adapted version of Allcutt and Sweeney }{ }^{8196} \text { knowledge, practice } \\
\text { and attitudes of HCPs towards solid food introduction survey }\end{array}$ & $\checkmark$ & $\checkmark$ & $\checkmark$ \\
\hline $\begin{array}{l}\text { Feedback on } \mathrm{CHErlsH} \mathrm{HCP} \\
\text { training and resources }\end{array}$ & Open-ended question and the AIM, IAM and FIM ${ }^{82}$ & & $\checkmark$ & \\
\hline Usefulness of HCP training & Self-report item & & & $\checkmark$ \\
\hline $\begin{array}{l}\text { Feedback on } \mathrm{CHErlsH} \text { parent- } \\
\text { level intervention and study } \\
\text { procedures }\end{array}$ & Open-ended questions and the AIM, IAM and FIM ${ }^{82}$ & & & $\checkmark$ \\
\hline Fidelity of intervention delivery & $\begin{array}{l}\text { Self-report checklist } \\
\text { Electronic prompt delivery records }\end{array}$ & & & $\checkmark$ \\
\hline
\end{tabular}

AIM, Acceptability of Intervention Measure; CHErlsH, Choosing Healthy Eating for Infant Health; FIM, Feasibility of Intervention Measure; HCP, healthcare professional; IAM; Intervention Appropriateness Measure.

credibility, audibility, confirmability and applicability. Qualitative data will be then integrated with quantitative data as part of the process evaluation, using a triangulation approach through the use of meta-matrices. ${ }^{98} 99$

\section{Quantitative analysis}

A study database for all self-report and anthropometric data will be created using SPSS Data Collection V.7 software. Descriptive summaries will be generated for HCP and parent outcomes and demographic variables. Means and SD will be calculated for continuous variables, frequencies will be calculated for categorical variables. Distributions of HCP and parent outcomes and variables, and potential outliers, will be examined. Data on recruitment, attrition, questionnaire response rates for parents and HCPs will similarly be descriptively summarised. Attrition and questionnaire response rates will also be descriptively examined in terms of parent demographics, including age, gender, relationship status, education and employment for parents. HCP age, gender, profession, number of years working in primary care and previous experience with infant feeding will also be examined in terms of HCP questionnaire response rates. Levels of missing data in returned questionnaires will be examined to evaluate feasibility and acceptability of data collection.

\section{DISCUSSION}

The aim of this feasibility study is to examine the acceptability and feasibility of an infant feeding intervention delivered by HCPs to parents at child vaccination visits in primary care, and the implementation strategy supporting delivery of this intervention. Developing and implementing interventions to prevent childhood obesity is a public health priority. ${ }^{16}$ The implementation and integration of childhood obesity prevention strategies into existing service structures have also been highlighted as research priorities. ${ }^{100}$ HCPs are uniquely placed to deliver interventions targeting parents' modifiable infant feeding behaviours to reduce child obesity risk. ${ }^{58}{ }^{59}$ Incorporating intervention components related to responsive feeding practices, and information about breast and formula feeding, introduction of solids and child dietary intake enables examination of a comprehensive intervention based on robust evidence $e^{465-70}$ and feeding guidelines. ${ }^{2151}$

While previous research indicates that implementation of interventions in primary care is acceptable to HCPs and parents, ${ }^{61}{ }^{62}$ issues around parent-HCP relationships and HCP capacity may influence the success of these interventions. ${ }^{63}$ The use of existing HCP contact points, which has been identified as a useful strategy by national programmes such as the NHCP, provides a unique opportunity to overcome some of these potential issues in implementation and delivery. This approach will enable the first examination of a comprehensive implementation strategy for HCPs to deliver the infant feeding intervention in practice, which will provide unique insights to inform future implementation strategies for child health in primary care. A further strength is the inclusion of a health economic assessment of the implementation strategy in the form of a cost-outcome description. While implementation process costs are identified as an important factor in implementation science theories and frameworks, ${ }^{101} 102$ these costs are understudied and often overlooked. ${ }^{103} 104$ Robust assessments of implementation costs are necessary to facilitate translation from research into practice. ${ }^{105}$ Overall findings relating to the feasibility and acceptability of the intervention and implementation strategy will inform the next steps of the CHErIsH study. If the project is successful, this is expected to involve evaluating the effects of the intervention in a definitive trial incorporating a comprehensive health economic evaluation. Findings from this feasibility study will also inform the feasibility of conducting an economic evaluation of CHErIsH in terms of the feasibility of capturing cost and outcome data in this population.

This feasibility study also has a number of potential limitations. There is potential for selection bias of 
participant recruitment and retention; however, a multimodal approach involving remote and in-person recruitment will be taken during the recruitment phase in an attempt to minimise this. Similarly, completion of study questionnaires can be completed by phone, in person or online, in an attempt to minimise retention. A further potential challenge is that parents of young infants may value information from other individuals, such as family and friends, over HCP-delivered information. ${ }^{46}$ Potential measurement issues relate to the use of parental and HCP self-report, which could be subject to recall and self-report biases. ${ }^{106}$ Self-report assessment of fidelity of the intervention will be supplemented by data from the electronic prompt system in the primary care system, and qualitative and quantitative findings from parent and HCP stakeholders will be integrated using a triangulation approach to further ensure confidence in our findings.

The long-term aim of the CHErIsH study is to contribute to the prevention of childhood obesity through appropriate infant feeding via an effective intervention delivered at primary care vaccination visits. Implementation and delivery of clear consistent infant feeding messages in routine primary care will address an important component of childhood obesity risk, ${ }^{20-24}$ which can be further implemented in multicomponent, national and international approaches to childhood obesity prevention. This feasibility study is the first examination of an infant feeding intervention, and HCP implementation strategy, to prevent childhood obesity delivered by HCPs at infant vaccination visits in a primary care practice.

\section{ETHICS AND DISSEMINATION}

Ethical approval was obtained for this feasibility study from the Clinical Research Ethics Committee of the Cork Teaching Hospitals (CREC), University College Cork. The CHErIsH study will be conducted in accordance with the principals of good clinical practice (GCP) and all site personnel have undergone training in GCP. The protocol and any amendments have been, and will be in the future, reviewed by the CREC and the Clinical Research Facility-Cork. Final results of this study will be disseminated in a peer-review journal, at relevant conferences, seminars and research meetings.

\section{Trial status}

Participant recruitment for this feasibility study will begin in January 2019.

\footnotetext{
Author affiliations

${ }^{1}$ School of Public Health, University College Cork National University of Ireland, Cork, Ireland

${ }^{2}$ School of Psychology, National University of Ireland-Galway National Centre for Biomedical Engineering Science, Galway, Ireland

${ }^{3}$ J.E. Cairnes School of Business \& Economics, National University of Ireland Galway, Galway, Ireland

${ }^{4}$ Department of Psychiatry, Cork University Hospital and University College Cork, Cork, Ireland

${ }^{5}$ APC Microbiome Institute, University College Cork, Cork, Ireland

${ }^{6}$ Public Health and Primary Care, University of Dublin Trinity College, Dublin, Ireland
}

${ }^{7}$ Health Behaviour Change Research Group, National University of Ireland, Galway, Ireland

${ }^{8}$ Whitaker Institute for Innovation and Societal Change, National University of Ireland Galway College of Science, Galway, Ireland

${ }^{9}$ Moorepark Food Research Centre, Teagasc, Cork, Ireland

${ }^{10}$ Mallow Primary Healthcare Centre, Cork, Ireland

${ }^{11}$ School of Psychology, University of Galway, Galway, UK

Acknowledgements The authors would like to thank Charlotte Griffin, Lisa Delaney and Jennifer Cooney who worked as research assistants on this project. We would like to thank the staff at the Mallow Primary Healthcare Centre, in particular Ms Ruth Haugh, Mr Carl Beame and Mr Conor Healy. We would like to thank Dr Phil Jennings and Ms Anne Pardy from the HSE National Healthy Childhood Programme, and Ms Joanne 0 Halloran from the HSE for their assistance in development and refinement of the infant feeding messages. We would like to thank Holly McGrath for her graphic design work on the intervention materials. We would also like to thank all the attendees of the 2018 CHErlsH Steering Committee meeting for their feedback and input on the project.

Contributors KM-S contributed to study design and development, and wrote the first draft of the paper and revised the paper with critical input from all authors. ET contributed to study design and development, and contributed to writing and revising the paper at all stages. MQ contributed to study design and development, and contributed to writing the first draft of the paper. CF, KON, TGD, MH, CK, $\mathrm{JMCS}$ and CS contributed to study design and development, and critically revised the manuscript. PMK, MB, CHa, JMH, ED, CHe, TH and SMcH contributed to the inception of the study and secured research funding, with PMK as project lead, and also contributed to study design and development, and critically revised the manuscript. All authors read, commented on and approved the final manuscript.

Funding This research is supported by a Health Research Board Interdisciplinary Capacity Enhancement Award (HRB ICE 2015-1026).

Competing interests None declared.

Patient consent for publication Not required.

Provenance and peer review Not commissioned; externally peer reviewed.

Open access This is an open access article distributed in accordance with the Creative Commons Attribution Non Commercial (CC BY-NC 4.0) license, which permits others to distribute, remix, adapt, build upon this work non-commercially, and license their derivative works on different terms, provided the original work is properly cited, appropriate credit is given, any changes made indicated, and the use is non-commercial. See: http://creativecommons.org/licenses/by-nc/4.0/.

\section{REFERENCES}

1. Simmonds M, Llewellyn A, Owen CG, et al. Predicting adult obesity from childhood obesity: a systematic review and meta-analysis. Obes Rev 2016;17:95-107.

2. Waters E, de Silva-Sanigorski A, Hall BJ, et al. Interventions for preventing obesity in children. Cochrane Database Syst Rev 2011:CD001871.

3. Verbeeten KC, Elks CE, Daneman D, et al. Association between childhood obesity and subsequent Type 1 diabetes: a systematic review and meta-analysis. Diabet Med 2011;28:10-18.

4. Bacha F, Gidding SS. Cardiac abnormalities in youth with obesity and type 2 diabetes. Curr Diab Rep 2016;16:62.

5. Maffeis C, Tatò L. Long-term effects of childhood obesity on morbidity and mortality. Horm Res 2001;55 Suppl 1(55 Suppl 1):42-5.

6. Reilly JJ, Kelly J. Long-term impact of overweight and obesity in childhood and adolescence on morbidity and premature mortality in adulthood: systematic review. Int J Obes 2011;35:891-8.

7. Cote AT, Harris KC, Panagiotopoulos C, et al. Childhood obesity and cardiovascular dysfunction. J Am Coll Cardiol 2013;62:1309-19.

8. Llewellyn A, Simmonds M, Owen CG, et al. Childhood obesity as a predictor of morbidity in adulthood: a systematic review and metaanalysis. Obes Rev 2016;17:56-67.

9. Ogden CL, Carroll MD, Lawman HG, et al. Trends in obesity prevalence among children and adolescents in the United States, 1988-1994 through 2013-2014. JAMA 2016;315:2292-9.

10. $\mathrm{Ng} \mathrm{M}$, Fleming $\mathrm{T}$, Robinson $\mathrm{M}$, et al. Global, regional, and national prevalence of overweight and obesity in children and adults during 
1980-2013: a systematic analysis for the Global Burden of Disease Study 2013. The Lancet 2014;384:766-81.

11. Organisation WH. Obesity and overweight: fact sheet. 2017. Available: http://www.who.int/mediacentre/factsheets/fs311/en/

12. Department of Health. Healthy Ireland: a framework for improved health and wellbeing 2013-2025, 2013.

13. Perry IJ, Millar SR, Balanda KP, et al. What are the estimated costs of childhood overweight and obesity on the island of Ireland? Cork: Safefood.

14. Growing Up in Ireland. Key findings: infant cohort (at 3 years). https://www.growingup.ie/pubs/OPEA125.pdf

15. Woo Baidal JA, Locks LM, Cheng ER, et al. Risk factors for childhood obesity in the first 1,000 days: a systematic review. Am J Prev Med 2016;50:761-79.

16. Blake-Lamb TL, Locks LM, Perkins ME, et al. Interventions for childhood obesity in the first 1,000 days a systematic review. Am J Prev Med 2016:50:780-9.

17. Wrotniak BH, Shults J, Butts S, et al. Gestational weight gain and risk of overweight in the offspring at age $7 \mathrm{y}$ in a multicenter, multiethnic cohort study. Am J Clin Nutr 2008;87:1818-24.

18. Baird J, Fisher D, Lucas P, et al. Being big or growing fast: systematic review of size and growth in infancy and later obesity. BMJ 2005;331:929-31.

19. Singhal A, Kennedy K, Lanigan J, et al. Dietary nucleotides and early growth in formula-fed infants: a randomized controlled trial. Pediatrics 2010;126:e946-e953.

20. DiSantis KI, Hodges EA, Johnson SL, et al. The role of responsive feeding in overweight during infancy and toddlerhood: a systematic review. Int J Obes 2011;35:480-92.

21. Pérez-Escamilla R, Segura-Pérez S, Lott M, et al. Feeding guidelines for infants and young toddlers: a responsive parenting approach. Durham, NC: Healthy Eating Research, 2017;52:223-31.

22. Steele RG, Jensen CD, Gayes LA, et al. Medium is the message: moderate parental control of feeding correlates with improved weight outcome in a pediatric obesity intervention. $J$ Pediatr Psychol 2014;39:708-17.

23. Brown A, Lee M. Maternal control of child feeding during the weaning period: differences between mothers following a baby-led or standard weaning approach. Matern Child Health $J$ 2011;15:1265-71.

24. Clark HR, Goyder E, Bissell P, et al. How do parents' child-feeding behaviours influence child weight? Implications for childhood obesity policy. J Public Health 2007;29:132-41.

25. Modrek S, Basu S, Harding M, et al. Does breastfeeding duration decrease child obesity? An instrumental variables analysis. Pediatr Obes 2017:12:304-11

26. Yan J, Liu L, Zhu Y, et al. The association between breastfeeding and childhood obesity: a meta-analysis. BMC Public Health 2014;14:1267.

27. Horta BL, Loret de Mola C, Victora CG. Long-term consequences of breastfeeding on cholesterol, obesity, systolic blood pressure and type 2 diabetes: a systematic review and meta-analysis. Acta Paediatr 2015;104:30-7.

28. Potera C. Prolonged bottle feeding raises childhood obesity risk. AJN, American Journal of Nursing 2011;111:17.

29. Wang J, Wu Y, Xiong G, et al. Introduction of complementary feeding before 4 months of age increases the risk of childhood overweight or obesity: a meta-analysis of prospective cohort studies. Nutr Res 2016;36:759-70.

30. de Beer M, Vrijkotte TG, Fall CH, et al. Associations of infant feeding and timing of linear growth and relative weight gain during early life with childhood body composition. Int J Obes 2015;39:586-92.

31. Pearce J, Langley-Evans SC. The types of food introduced during complementary feeding and risk of childhood obesity: a systematic review. Int J Obes 2013;37:477-85.

32. Nicklaus S. Children's acceptance of new foods at weaning. Role of practices of weaning and of food sensory properties. Appetite 2011;57:812-5.

33. Taylor RW, losua E, Heath AM, et al. Eating frequency in relation to $\mathrm{BMI}$ in very young children: a longitudinal analysis. Public Health Nutr 2017;20:1372-9.

34. Koletzko B, von Kries R, Closa R, et al. Lower protein in infant formula is associated with lower weight up to age $2 \mathrm{y}$ : a randomized clinical trial. Am J Clin Nutr 2009;89:1836-45.

35. Weber M, Grote V, Closa-Monasterolo R, et al. Lower protein content in infant formula reduces $\mathrm{BMI}$ and obesity risk at school age: follow-up of a randomized trial. Am J Clin Nutr 2014;99:1041-51.

36. Huang J, Zhang Z, Wu Y, et al. Early feeding of larger volumes of formula milk is associated with greater body weight or overweight in later infancy. Nutr J 2018;17:12.
37. McCrory C, Layte R. Breastfeeding and risk of overweight and obesity at nine-years of age. Soc Sci Med 2012;75:323-30.

38. Shloim N, Vereijken C, Blundell P, et al. Looking for cues - infant communication of hunger and satiation during milk feeding. Appetite 2017;108:74-82.

39. Hodges EA, Johnson SL, Hughes SO, et al. Development of the responsiveness to child feeding cues scale. Appetite 2013;65:210-9.

40. Hodges EA, Wasser HM, Colgan BK, et al. Development of feeding cues during infancy and toddlerhood. MCN Am J Matern Child Nurs 2016;41:244-51.

41. Birch LL, Ventura AK. Preventing childhood obesity: what works? Int J Obes 2009;33(S1):S74-S81.

42. Birch LL, Doub AE. Learning to eat: birth to age 2 y. Am J Clin Nutr 2014:99:723S-8.

43. Gibbs BG, Forste R, status S. infant feeding practices and early childhood obesity. Pediatric obesity 2014;9:135-46.

44. Cameron AJ, Ball K, Hesketh KD, et al. Variation in outcomes of the Melbourne Infant, Feeding, Activity and Nutrition Trial (InFANT) Program according to maternal education and age. Prev Med 2014;58:58-63.

45. Wijndaele K, Lakshman R, Landsbaugh JR, et al. Determinants of early weaning and use of unmodified cow's milk in infants: a systematic review. J Am Diet Assoc 2009;109:2017-28.

46. Matvienko-Sikar K, Kelly C, Sinnott C, et al. Parental experiences and perceptions of infant complementary feeding: a qualitative evidence synthesis. Obes Rev 2018;19.

47. Swyden K, Sisson SB, Morris AS, et al. Association between maternal stress, work status, concern about child weight, and restrictive feeding practices in preschool children. Matern Child Health J 2017;21:1349-57.

48. Harrison M, Brodribb W, Hepworth J. A qualitative systematic review of maternal infant feeding practices in transitioning from milk feeds to family foods. Matern Child Nutr 2017;13:e12360.

49. Wojcicki JM, Gugig R, Kathiravan S, et al. Maternal knowledge of infant feeding guidelines and label reading behaviours in a population of new mothers in San Francisco, California. Matern Child Nutr 2009;5:223-33.

50. Organisation WH, UNICEF. Global breastfeeding scorecard, 2017: tracking progress for breastfeeding policies and programmes, 2017.

51. Organisation WH. Global strategy for infant and young child feeding. Geneva, Switzerland, 2003.

52. Schiess S, Grote V, Scaglioni S, et al. Introduction of complementary feeding in 5 European countries. $J$ Pediatr Gastroenterol Nutr 2010;50:92-8.

53. Kuo AA, Inkelas M, Slusser WM, et al. Introduction of solid food to young infants. Matern Child Health J 2011;15:1185-94.

54. Clayton HB, Li R, Perrine CG, et al. Prevalence and reasons for introducing infants early to solid foods: variations by milk feeding type. Pediatrics 2013;131:e1108-14.

55. Purdy J, McAvoy H, Cotter N. Breastfeeding on the island of Ireland. Dublin: Institute of Public Health in Ireland, 2017.

56. World Health Organisation. World health statistics. Geneva: WHO, 2013.

57. Castro PD, Kearney J, Layte R. A study of early complementary feeding determinants in the Republic of Ireland based on a crosssectional analysis of the Growing Up in Ireland infant cohort. Public Health Nutr 2015;18:292-302.

58. Matvienko-Sikar K, Toomey E, Delaney L, et al. Effects of healthcare professional delivered early feeding interventions on feeding practices and dietary intake: A systematic review. Appetite 2018;123:56-71.

59. Gorin AA, Wiley J, Ohannessian CM, et al. Steps to growing up healthy: a pediatric primary care based obesity prevention program for young children. BMC Public Health 2014;14:72.

60. Health Protection Surveillance Centre. Early childhood immunisation uptake statistics Q1 1999-Q2 2018 Summary. Dublin.

61. Ayton J, Howes F, Hansen E, et al. Evaluating the prevention of premature cessation of exclusive breastfeeding in the general practice setting during the scheduled child immunisation consultation: a pilot study. Aust J Prim Health 2015;21:299-304.

62. Doorley E, Young C, O'Shea B, et al. Is primary prevention of childhood obesity by education at 13-month immunisations feasible and acceptable? Results from a general practice based pilot study. Ir Med J 2015;108:13-15

63. Toomey E, Byrne M, Houghton C, et al. Health-care professional and parental views and experiences of implementing infant feeding interventions: a qualitative evidence synthesis. The Lancet 2018;392(S87):S87. 
64. Craig P, Dieppe P, Macintyre S, et al. Developing and evaluating complex interventions: The new Medical Research Council guidance. Int J Nurs Stud 2013;50:587-92.

65. Czajkowski SM. Obesity Related Behavioral Intervention Trials (Orbit): translating basic behavioral \& social sciences discoveries into interventions to reduce obesity. Ann Behav Med 2013;45:S70.

66. Powell BJ, Waltz TJ, Chinman MJ, et al. A refined compilation of implementation strategies: results from the Expert Recommendations for Implementing Change (ERIC) project. Implement Sci 2015;10:21.

67. Francis $\mathrm{JJ}$, Johnston $\mathrm{M}$, Robertson $\mathrm{C}$, et al. What is an adequate sample size? Operationalising data saturation for theory-based interview studies. Psychol Health 2010;25:1229-45.

68. Matvienko-Sikar K, Byrne M, Kelly C, et al. Developing an infant feeding core outcome set for childhood obesity prevention. The Lancet 2018;392(S59):S59.

69. Matvienko-Sikar K, Griffin C, McGrath N, et al. Developing a core outcome set for childhood obesity prevention: A systematic review. Matern Child Nutr 2018:e12680.

70. Toomey E, Matvienko-Sikar K, Heary C, et al. Intervention fidelity within trials of infant feeding behavioral interventions to prevent childhood obesity: a systematic review. Ann Behav Med 2019;53:75-97.

71. Michie S, van Stralen MM, West R. The behaviour change wheel: a new method for characterising and designing behaviour change interventions. Implement Sci 2011;6:1-12.

72. Michie S, Richardson M, Johnston M, et al. The behavior change technique taxonomy (v1) of 93 hierarchically clustered techniques: building an international consensus for the reporting of behavior change interventions. Ann Behav Med 2013;46:81-95.

73. Ajzen I. The theory of planned behavior. Organ Behav Hum Decis Process 1991;50:179-211.

74. Bandura A. Social cognitive theory: an agentic perspective. Annu Rev Psychol 2001;52:1-26.

75. Bowen M. The use of family theory in clinical practice. Compr Psychiatry 1966;7:345-74.

76. Hamilton K, Daniels L, White KM, et al. Predicting mothers' decisions to introduce complementary feeding at 6 months. An investigation using an extended theory of planned behaviour. Appetite 2011;56:674-81.

77. Swanson V, Nicol H, Mclnnes R, et al. Developing maternal selfefficacy for feeding preterm babies in the neonatal unit. Qual Health Res 2012;22:1369-82.

78. Matvienko-Slkar K, Toomey E, Delaney L, et al. Effects of early infant feeding interventions on parental feeding practices: A systematic review. 24th European Congress on Obesity Obesity Facts 2017.

79. Skelton JA, Buehler C, Irby MB, et al. Where are family theories in family-based obesity treatment?: conceptualizing the study of families in pediatric weight management. Int $J$ Obes 2012;36:891-900.

80. Proctor EK, Powell BJ, McMillen JC. Implementation strategies: recommendations for specifying and reporting. Implement Sci 2013;8:139

81. Bellg AJ, Borrelli B, Resnick B, et al. Enhancing treatment fidelity in health behavior change studies: best practices and recommendations from the NIH Behavior Change Consortium. Health Psychol 2004;23:443-51.

82. Weiner B, Dorsey C, Halko H, et al. Psychometric assessment of three newly developed implementation outcome measures. Implement Sci 2018;13.

83. Drummond MF, E al. Methods for the economic evaluation of health care programmes, 2015

84. Ferguson B. Methods for the economic-evaluation of health-care programs - Drummond,Mf, Stoddart,Gl, Torrance,Gw. Can Public Pol 1988;14:226-7.
85. Information IHaQA. Guidelines for the economic evaluation of health technologies in Ireland: Authority HlaQ, 2010.

86. Chisholm D, Knapp MRJ, Knudsen HC, et al. Client SocioDemographic and Service Receipt Inventory - European Version: development of an instrument for international research. British Journal of Psychiatry 2000;177:s28-s33.

87. Herdman M, Gudex C, Lloyd A, et al. Development and preliminary testing of the new five-level version of EQ-5D (EQ-5D-5L). Qual Life Res 2011;20:1727-36.

88. Mitchell PM, Al-Janabi H, Byford S, et al. Assessing the validity of the ICECAP-A capability measure for adults with depression. BMC Psychiatry 2017;17:46.

89. Denney-Wilson E, Laws R, Russell CG, et al. Preventing obesity in infants: the Growing healthy feasibility trial protocol. BMJ Open 2015:5:e009258.

90. Thompson AL, Mendez MA, Borja JB, et al. Development and validation of the infant feeding style questionnaire. Appetite 2009;53:210-21.

91. Horodynski MA, Baker S, Olson B, et al. Healthy Babies through Infant-Centered Feeding. Society of Nutrition Education's 44th Conference, Washington, DD, 2012.

92. Järbrink K, Fombonne E, Knapp M. Measuring the parental, service and cost impacts of children with autistic spectrum disorder: a pilot study. J Autism Dev Disord 2003;33:395-402.

93. Cohen S, Kamarck T, Mermelstein R. A global measure of perceived stress. J Health Soc Behav 1983;24:385-96.

94. Benediktsson I, McDonald S, Tough S. Examining the psychometric properties of three standardized screening tools in a pregnant and parenting population. Matern Child Health J 2017;21:253-9.

95. Group WMGRS. WHO Child Growth Standards: Length/height-forage, weight-for-age, weight-for-length, weight-for-height and body mass index-for-age: Methods and development. Geneva, 2006.

96. Allcutt C, Sweeney M-R. An exploration of knowledge, attitudes and advice given by health professionals to parents in Ireland about the introduction of solid foods. A pilot study. BMC Public Health 2010;10:201-8.

97. Braun V, Clarke V. Using thematic analysis in psychology. Qual Res Psychol 2006;3:77-101.

98. Guetterman TC, Fetters MD, Creswell JW. Integrating quantitative and qualitative results in health science mixed methods research through joint displays. Ann Fam Med 2015;13:554-61.

99. Wendler MC. Triangulation using a meta-matrix. J Adv Nurs 2001;35:521-5.

100. Hennessy M, Byrne M, Laws R, et al. Childhood obesity prevention: priority areas for future research and barriers and facilitators to knowledge translation, coproduced using the nominal group technique. Transl Behav Med 2018.

101. Proctor E, Silmere H, Raghavan R, et al. Outcomes for implementation research: conceptual distinctions, measurement challenges, and research agenda. Adm Policy Ment Health 2011;38:65-76.

102. Damschroder LJ, Aron DC, Keith RE, et al. Fostering implementation of health services research findings into practice: a consolidated framework for advancing implementation science. Implement Sci 2009;4:50.

103. Ginexi EM, Hilton TF. What's next for translation research? Eval Health Prof 2006;29:334-47.

104. Saldana L, Chamberlain P, Bradford WD, et al. The cost of implementing new strategies (COINS): A method for mapping implementation resources using the stages of implementation completion. Child Youth Serv Rev 2014;39:177-82.

105. Ritzwoller DP, Sukhanova A, Gaglio B, et al. Costing behavioral interventions: a practical guide to enhance translation. Ann Behav Med 2009;37:218-27.

106. Stone AA, Turkkan JS, Bc A, et al. The Science of Self-report: Implications for Research and Practice. Mahwah, NJ: Lawrence Erlbaum Associates, 2000. 